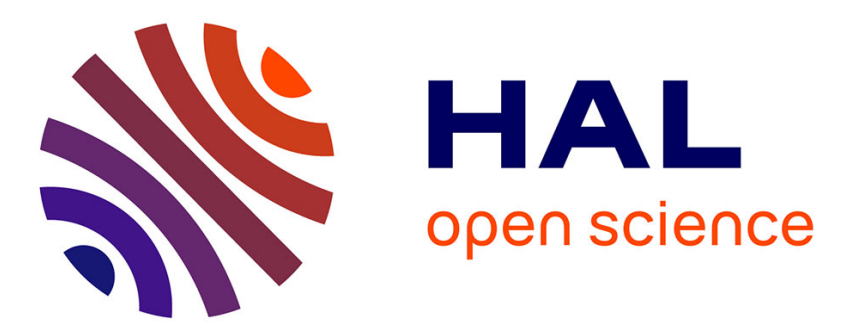

\title{
Modeling the effect of initial planting density on within tree variation of stiffness in loblolly pine
}

\author{
Antony, Laurence Schimleck, Jordan, Richard Daniels, Clark
}

\section{To cite this version:}

Antony, Laurence Schimleck, Jordan, Richard Daniels, Clark. Modeling the effect of initial planting density on within tree variation of stiffness in loblolly pine. Annals of Forest Science, 2012, 69 (5), pp.641-650. 10.1007/s13595-011-0180-1 . hal-00930752

\section{HAL Id: hal-00930752 https://hal.science/hal-00930752}

Submitted on 1 Jan 2012

HAL is a multi-disciplinary open access archive for the deposit and dissemination of scientific research documents, whether they are published or not. The documents may come from teaching and research institutions in France or abroad, or from public or private research centers.
L'archive ouverte pluridisciplinaire HAL, est destinée au dépôt et à la diffusion de documents scientifiques de niveau recherche, publiés ou non, émanant des établissements d'enseignement et de recherche français ou étrangers, des laboratoires publics ou privés. 


\title{
Modeling the effect of initial planting density on within tree variation of stiffness in loblolly pine
}

\author{
Finto Antony • Laurence R. Schimleck • Lewis Jordan • \\ Richard F. Daniels • Alex Clark III
}

Received: 4 September 2011 / Accepted: 28 December 2011 / Published online: 27 January 2012

(C) INRA / Springer-Verlag France 2012

\begin{abstract}
- Context Modulus of elasticity (MOE) is an important mechanical property determining the end-use and value of loblolly pine (Pinus taeda L.) lumber.

- Aim In this study, a model was developed to predict the within tree variation of MOE, from pith-to-bark and stumpto-tip, using data collected from a 21-year-old unthinned stand where trees were planted under seven initial stand density levels (746-2,243 trees/hectare).

- Methods The study was laid out in a randomized complete block design, with seven levels of initial planting density, replicated three times. Seven trees were destructively sampled from each plot, and bolts were cut from each tree at heights of 2.4, 7.3, and $12.2 \mathrm{~m}$. Static bending samples (of dimension

\section{Handling Editor: Jean-Michel Leban}

Contribution of co-authors Finto Antony: As first author of the paper, I compiled the data, analyzed it and wrote the paper.

Laurence R. Schimleck: This author contributed significantly to the introduction and discussion section of paper. In addition, this author thoroughly reviewed the final manuscript.

Lewis Jordan: Contributed significantly to the data analysis portion of manuscript and thoroughly reviewed the manuscript.

Richard F. Daniels: Coordinated the research project and provided

valuable advice during the model development portion of the manuscript. Alex Clark III: Coordinated the research project and provided valuable advice during the model development portion of the manuscript.
\end{abstract}

F. Antony $(\bowtie) \cdot$ L. R. Schimleck $\cdot$ R. F. Daniels

Warnell School of Forestry and Natural Resources,

The University of Georgia,

Athens, GA 30602, USA

e-mail: fintoa@warnell.uga.edu

\section{Jordan}

Southern Timberlands R\&D, Weyerhaeuser Company,

P.O. Box 2288, Columbus, MS 39704, USA

A. Clark III

USDA Forest Service,

Athens, GA 30602, USA
$2.5 \times 2.5 \times 40.6 \mathrm{~cm})$ representing pith-to-bark variation were cut from each bolt and MOE measured. A three-parameter logistic function was used to model the pith-to-bark variation in stiffness with distance from pith as an explanatory variable. - Results Based on the final fitted model, it was found that the asymptotic parameter (maximum outerwood $\mathrm{MOE}=13.48 \mathrm{GPa}$ ) was not influenced by sampling height, initial planting density, and stem slenderness. However, the inflection and scale parameters were significantly influenced by these variables.

- Conclusions In summary, we found that initial planting density had a significant influence on the amount of corewood produced with higher initial planting densities producing a lower proportion of corewood as indicated by a linear decrease in inflection point with an increase in planting density.

Keywords Loblolly pine · Corewood - Outerwood . Stiffness $\cdot$ Pinus taeda $\mathrm{L}$

\section{Introduction}

Modulus of elasticity (MOE) or stiffness is a measure of the deformation that wood undergoes when subject to an applied load, and it is measured as a ratio between stress and strain. It is a property of particular interest to growers and processors of structural lumber as it determines the end-use and value of lumber cut from a tree. In loblolly pine (Pinus taeda L.) trees, an increasing trend in MOE has been observed from pith-to-bark (corewood-to-outerwood) and a decreasing trend from butt-to-tip (Megraw et al. 1999; Antony et al. 2011). The stiffness of wood from loblolly pine largely depends upon its density and microfibril angle (MFA) (Megraw et al. 1999; Evans and Ilic 2001; Downes et al. 2002), with high MFA and low specific gravity near the pith (corewood zone) associated with low MOE and low 
MFA and high specific gravity with stiffer wood near the bark (outerwood zone) (Larson et al. 2001).

During the last two decades in the southern USA, management practices applied to loblolly pine stands have become more intensive. The use of genetically improved planting stock at varying planting densities with multiple applications of herbicide to control competition and fertilizer application at planting and mid-rotation has become common and is expected to continue in the future (Wear and Greis 2002). Intensive management practices have resulted in loblolly pine trees attaining merchantable size much quicker and hence reducing rotation age. It has been reported that young fast grown pines contain large volumes of low quality corewood, and lumber produced from existing short rotation plantations may not have the stiffness required to meet design requirements for dimension lumber (MacPeak et al. 1990; Biblis et al. 1993; Plomion et al. 2001; Watt et al. 2009; Watt et al. 2010). Biblis et al. (1993) reported that the strength and stiffness of lumber samples from plantation grown loblolly pine trees of age 25,30 , and 35 years failed to meet the design requirement values prescribed by Southern Pine Inspection Bureau for their visual grade lumber.

Controlling initial planting density is an important tool in the management of loblolly pine plantations and influences both the yield and quality of wood produced. Rapid diameter growth was observed in loblolly pine trees planted at wide initial spacing (Baldwin et al. 2000; Sharma et al. 2002; Zhao et al. 2011), which resulted in the production of a larger corewood zone (Clark and Saucier 1989). Biblis and Meldahl (2006) observed no significant difference in average MOE of small, clear wood specimens from two 20-year-old loblolly pine plantations; one was planted at a density of 2,989 trees/hectare (TPH) and the other at $746 \mathrm{TPH}$. In another study, Clark et al. (2008) observed significant differences in MOE of static bending samples collected from the mid-point of the first $\log$ (i.e., $2.4 \mathrm{~m}$ ) with different initial planting densities but did not observe differences in samples collected from the mid-point of the second and third logs (7.3 and $12.2 \mathrm{~m}$, respectively). They reported a $12-14 \%$ reduction in MOE for samples from $2.4 \mathrm{~m}$ for trees planted at $746 \mathrm{TPH}$ compared to trees planted at 1,494, 1,793, and 2,243 TPA.

Accurate prediction of within tree variation of MOE is important for foresters as this information can be used for product categorization and hence assists in maximizing utilization efficiency. Models to predict changes in MOE with height by wood type (corewood and outerwood) were developed by Wang (2003) and Antony et al. (2011). Little work has been conducted on the modeling aspects of within tree variation in MOE, both from pith-to-bark and from stump-to-tip in loblolly pine grown under a wide range of initial planting densities. The data used by Clark et al. (2008) provide an opportunity to model the within tree variation in $\mathrm{MOE}$ of loblolly pine trees grown under a range of planting densities (746-2,243 TPH). The objective of the study was to (1) model the within tree variation in MOE and (2) analyze the influence of initial planting density on within tree variation in MOE.

\section{Materials and methods}

\subsection{Data}

Trees sampled from a loblolly pine spacing study located at Rincon, GA, USA (latitude $=32.26^{\circ} \mathrm{N}$; longitude $=81.26^{\circ} \mathrm{W}$; elevation $=20 \mathrm{~m}$ ) on the Atlantic Coastal Plain were used in this study. The study was established in 1984 and laid out in a randomized complete block design, with seven initial spacing treatments: $3.7 \times 3.7(746 \mathrm{TPH}), 3 \times 3.7(897 \mathrm{TPH}), 2.4 \times 3.7$ (1,121 TPH), $2.4 \times 3(1,344 \mathrm{TPH}), 1.8 \times 3.7(1,494 \mathrm{TPH}), 1.8 \times$ $3(1,793 \mathrm{TPH})$, and $1.8 \times 2.4 \mathrm{~m}(2,243 \mathrm{TPH})$, each replicated in three blocks. Each plot in the study was planted with seedlings from loblolly pine family $7-56$ on commercially prepared beds and consisted of eight rows with eight trees per row. All plots received $56.7 \mathrm{~kg}$ of diammonium phosphate and herbaceous weed control using broadcast application of herbicide at the time of planting. In addition, each plot received herbaceous weed control in the first and second year after planting and $136 \mathrm{~kg}$ of urea at ages 5 and 10 . The stand was not thinned and thus maintained the initial spacing throughout the study.

Seven trees with diameter at breast height (DBH, $1.37 \mathrm{~m}$ ) $\geq 20.32 \mathrm{~cm}$ were destructively sampled from each plot in 2005 (at stand age 21). The trees sampled were selected in proportion to the diameter distribution of all the trees in the plot, where the proportion was the ratio of the number of trees in each $2.5 \mathrm{~cm}$ DBH class to the total number of trees in the plot. A total of 133 trees were sampled in the study (as opposed to the possible $147(7 \times 3 \times 7)$ as one replication from two spacing treatments $(3 \times 3.7 \mathrm{~m}$ and $1.8 \times 3.7 \mathrm{~m}$, i.e., 14 trees) were missing. The DBH and total height of the trees sampled from each plot were measured, and the summary information is presented in Table 1 .

Table 1 The observed mean diameter at breast height and total height of trees by initial planting density with corresponding standard deviation in parenthesis

\begin{tabular}{lcc}
\hline $\begin{array}{l}\text { Planting density } \\
\text { (trees/hectare) }\end{array}$ & Diameter at $1.4 \mathrm{~m}(\mathrm{~cm})$ & Total height (m) \\
\hline 746 & $29.72(3.93)$ & $25.62(1.29)$ \\
897 & $27.41(3.48)$ & $25.80(1.17)$ \\
1,121 & $25.92(3.69)$ & $25.96(1.37)$ \\
1,344 & $25.13(3.13)$ & $25.14(1.33)$ \\
1,494 & $24.57(2.95)$ & $25.27(1.89)$ \\
1,793 & $24.67(3.09)$ & $25.39(1.23)$ \\
2,243 & $24.12(3.07)$ & $24.92(1.71)$ \\
\hline
\end{tabular}


From each sampled tree, a $0.6-\mathrm{m}$ long bolt was cut from 2.1 to $2.7 \mathrm{~m}, 7.0$ to $7.6 \mathrm{~m}$, and from 11.9 to $12.5 \mathrm{~m}$ (with mid-points at $2.4,7.3$, and $12.2 \mathrm{~m}$, respectively) from the stem, such that each bolt represented the mid-point of standard 4.9-m long logs. The mid-point diameter (both inside and outside bark) of each bolt was also recorded. The bolts were frozen and stored until further processing into short clear static bending samples.

From each $0.6-\mathrm{m}$ bolt, a $3.8-\mathrm{cm}$ thick radial slab was cut from bark-to-bark through the pith, and the slabs were kiln dried to $12 \%$ moisture content. After drying, each slab was split in to half through the pith and clear static bending samples with dimensions 2.5 (radial) $\times 2.5$ (tangential) $\times 40.6 \mathrm{~cm}$ (longitudinal) were cut contiguously from each half of the slab, starting from the bark. Any static bending samples containing pith were not used for further testing. A total of 1,663 defect-free static bending samples were used in this study. Approximately, one to five samples were obtained from each side of bolts cut from each sampled height. The number of samples obtained depends on the inside bark diameter of the tree at each sampling height.

The static bending samples were tested using a 3-point loading Tinius Olsen test machine using $35.6 \mathrm{~cm}$ span with pith upwards at $12 \%$ equilibrium moisture content following the procedure suggested by ASTM D143-94 (ASTM Standard D143, 2009) for testing alternative sized samples. A continuous load was applied at a head speed of $0.18 \mathrm{~cm} / \mathrm{min}$, rather than $0.13 \mathrm{~cm} / \mathrm{min}$ to reduce test time. After testing, MOE of each sample was calculated using the procedure outlined in ASTM D143-94 (ASTM Standard D143, 2009). Static bending samples cut from each side of the $3.8-\mathrm{cm}$ thick slab approximately matched each other (approximately included the same ring numbers), and hence, the data collected from matching samples were averaged by position from bark. Using the inside bark diameter measured at the mid-point of each $0.6 \mathrm{~m}$ bolt (at 2.4, 7.3 , and $12.2 \mathrm{~m}$ ) and the fact that each static bending sample was $2.54 \mathrm{~cm}$ in thickness, we computed the distance from pith (in $\mathrm{cm}$ ) of each static bending sample used in the study.

\subsection{Model development}

The MOE profiles (with distance from pith) of trees within each spacing by height combination are presented in Fig. 1. A consistent pattern was observed in MOE variation from pithto-bark at all sampled heights, with a rapid increase in MOE near the pith and approaching an upper asymptote near the bark (Megraw et al. 1999). Several candidate models were fitted to the data, and their performance was compared based on Akaike information criterion (AIC), a commonly used model selection criterion. The functional forms used were (1) linear (AIC $=$ 3,222.34), (2) quadratic (AIC $=3,199.24)$, (3) Asymptotic $(\mathrm{AIC}=3,204.26)$, and (4) logistic $(\mathrm{AIC}=3,186.34)$. A threeparameter logistic model was selected as the best model based on the fit statistics of the candidate models (the model with smallest AIC) to explain the mean trend in MOE variation with distance from pith. The selected model is

$y(R)=\mathrm{f}(\beta, R)=\frac{\beta_{0}}{1+e^{\left(\frac{\beta_{1}-R}{\beta_{2}}\right)}}$

where $y(R)$ is the measured MOE at distance $R$ in centimeters from pith, $\boldsymbol{\beta}_{0}$ is the asymptote as $R \rightarrow \infty$, which will be equivalent to maximum outerwood MOE, $\boldsymbol{\beta}_{1}$ corresponds to the distance from pith at which $\mathrm{MOE}$ is $\beta_{0} / 2$, i.e., the inflection point of the curve, and $\boldsymbol{\beta}_{2}$ corresponds to the distance (radius) between the inflection point $\left(\boldsymbol{\beta}_{1}\right)$ and the point from the pith where MOE is $\beta_{0} /\left(1+e^{-1}\right)$, i.e., the scale parameter (Pinheiro and Bates 2000).

After identifying an appropriate function to explain the data, the next step was to model the mean trend with sufficient generality by taking care of all available covariates, i.e., a saturated parameter specification (Littell et al. 2000). The observed trend in MOE with distance from pith varies with sampling height and initial planting density (TPH; Fig. 1). It was evident from Fig. 1 that the observed MOE profiles changed considerably with respect to sampling height; for example, the maximum MOE achieved decreased with sampling height. Maximum MOEs of $14.37,14.06$, and $11.65 \mathrm{GPa}$ were observed at heights of $2.4,7.3$, and $12.2 \mathrm{~m}$ respectively, and indicated that the value of parameter $\boldsymbol{\beta}_{0}$ might depend on sampling height.

In order to explore the trends in parameters with tree height and TPH, model 1 was fitted separately to each height by TPH combination, and the estimated parameters were subjected to exploratory data analysis (Fig. 2). Based on Fig. 2, it is clear that the estimates of $\boldsymbol{\beta}_{0}$ and $\boldsymbol{\beta}_{1}$ decreased with tree height ( $\log _{\mathrm{e}}$ of tree height), and parameter $\boldsymbol{\beta}_{2}$ increased a little with height. On the other hand, any trend in $\boldsymbol{\beta}_{0}, \boldsymbol{\beta}_{1}$, and $\boldsymbol{\beta}_{2}$ with TPH was absent (Fig. 2). Further analysis was conducted to characterize the influence of covariates TPH, DBH, and total height on parameters by fitting model 1 as a nonlinear mixed model with tree level random effects in it (tree level random effects, empirical best linear unbiased predictors (EBLUP's), were estimated for all three parameters in the model). The estimated tree level random effects of each parameter were subjected to exploratory analysis (Fig. 3). An increasing trend in $\boldsymbol{\beta}_{0}$ and a decreasing trend in $\boldsymbol{\beta}_{1}$ and $\boldsymbol{\beta}_{2}$ with TPH was evident from this plot. Based on the evidence from past studies in loblolly pine (He 2004) and radiata pine (Watt and Zoric 2010), we used stem slenderness $(\mathrm{SL}, \mathrm{cm} / \mathrm{m}$, a ratio of tree DBH and total height) as an explanatory variable in this study rather than DBH and total tree height separately. A decreasing trend in $\boldsymbol{\beta}_{0}$ and an increasing trend in $\boldsymbol{\beta}_{1}$ and $\boldsymbol{\beta}_{2}$ with slenderness were evident from Fig. 3 . Based on these observations, the mean structure of the model was changed by expressing $l$ th $(l=0,1,2)$ parameter 
in model 1 as a linear function of $\log _{\mathrm{e}}$ height, $\log _{10} \mathrm{TPH}$, and $\mathrm{SL}$ as $\beta_{l}=\beta_{l 0}+\beta_{l 1} \log _{e}$ (height) $+\beta_{l 2} \log _{10}(\mathrm{TPH})+\beta_{l 3} \mathrm{SL}$.

The data collected in this study follow a hierarchical structure with the trees selected representing a random sample of all trees in the corresponding plot. The plots selected represent a random sample of all plots in the corresponding block and blocks selected represented a random sample of all blocks available from the stand. The mixed model framework (Pinheiro and Bates 2000) could be potentially utilized to account for multilevel heterogeneity by expressing the parameters in the model as mixed effects. Let $y_{i j k l m}$ represents the $m$ th MOE observation measured from pith at $l$ th tree height from $k$ th tree in the $j$ th plot of the $i$ th block; the nonlinear mixed model can be represented as

$y_{i j k l m}=\frac{\beta_{0, i j k}}{1+e^{\left(\frac{\beta_{1, i j k}>-R_{i j k l m}}{\beta_{2, i j k}}\right)}}+\varepsilon_{i j k l m}$

Following Pinheiro and Bates (2000), the parameters in model 2 can be expressed as

Here,

$$
\beta_{i j k}=\left[\begin{array}{l}
\beta_{0, i j k} \\
\beta_{1, i j k} \\
\beta_{2, i j k}
\end{array}\right]=\underbrace{\left[\begin{array}{l}
\beta_{0} \\
\beta_{1} \\
\beta_{2}
\end{array}\right]}_{\beta}+\underbrace{\left[\begin{array}{l}
b_{0 i} \\
b_{1 i} \\
b_{2 i}
\end{array}\right]}_{\mathrm{b}_{\mathrm{i}}}+\underbrace{\left[\begin{array}{l}
b_{0 i j} \\
b_{1 i j} \\
b_{2 i j}
\end{array}\right]}_{\mathrm{b}_{i j}}+\underbrace{\left[\begin{array}{l}
b_{0 i j k} \\
b_{1 i j k} \\
b_{2 i j k}
\end{array}\right]}_{\mathrm{b}_{i j k}}
$$

where $\mathbf{b}_{i}, \mathbf{b}_{i j}$, and $\mathbf{b}_{i j k}$ are the block, plot, and tree level random effect vectors, and $\beta$ is the fixed-effect parameter vector.
The random effects and the within-plot error term were assumed to be distributed normally as $\mathrm{b}_{i} \sim N\left(0, \Psi_{1}\right), \mathrm{b}_{i j} \sim$ $N\left(0, \Psi_{2}\right), \mathrm{b}_{i j k} \sim N\left(0, \Psi_{3}\right)$, and $\varepsilon_{i j k l m} \sim N\left(0, \sigma^{2}\right)$. Here $\Psi_{1}$, $\Psi_{2}$, and $\Psi_{3}$ were variance-covariance matrices representing different levels of random effects (block, plot, and tree). A full model with random effects associated with all the parameters in the model considered first by assuming a diagonal variance-covariance matrix structure for random effects and an independent structure to within tree error.

The data were collected from different heights within a tree and at continuous radial distance from pith-to-bark at any height, and it is plausible to assume that two measurements taken at any point in a tree are correlated with each other, with measurements close together more highly correlated than those farther apart. The independent matrix structure associated with the within-tree error was relaxed $\varepsilon_{i j k l m} \sim$ $N\left(0, \sigma^{2} \Lambda_{i j k l}\right)$. This will enable us to explain the heteroscedasticity in the data and serial correlation across measurements successfully. Since evidence of any heteroscedasticity was absent (based on the plot of standardized residuals; not presented here), no variance functions were used in the model. In order to account for correlation across measurements within a tree, a random height effect was added with each parameter in the model, which will account for correlation across measurements taken at different heights, and a continuous first order autocorrelation structure was used to account for correlation across measurements taken along the radius at a specific height. The assumed correlation structure performed better (in terms of fit statistics) than any twodimensional spatial correlation structure attempted (spatial

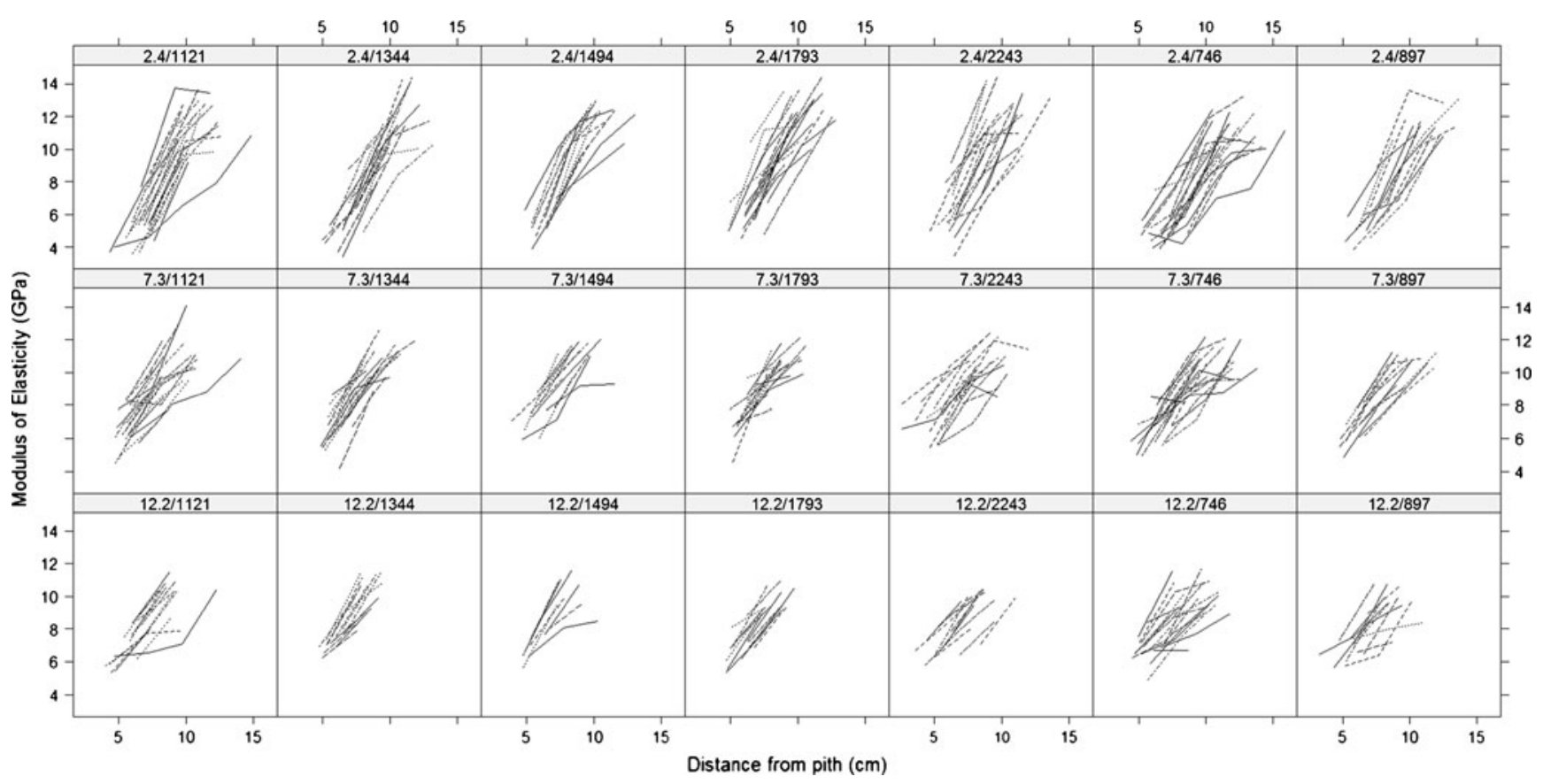

Fig. 1 Plot showing the variation in modulus of elasticity (GPa) with distance from pith of the tree by sampling height (mid points of $4.9 \mathrm{~m}$ log) and seven spacing treatments (trees/hectare) 
Fig. 2 Plot showing the trend in estimated parameters with height (ln of height) and initial planting density $\left[\log _{10}\right.$ of trees/ hectare (TPH)] from fitting a three-parameter logistic model separately to each height by initial planting density combinations. The open circles are estimated parameters and dashed lines are smoothed LOESS curves
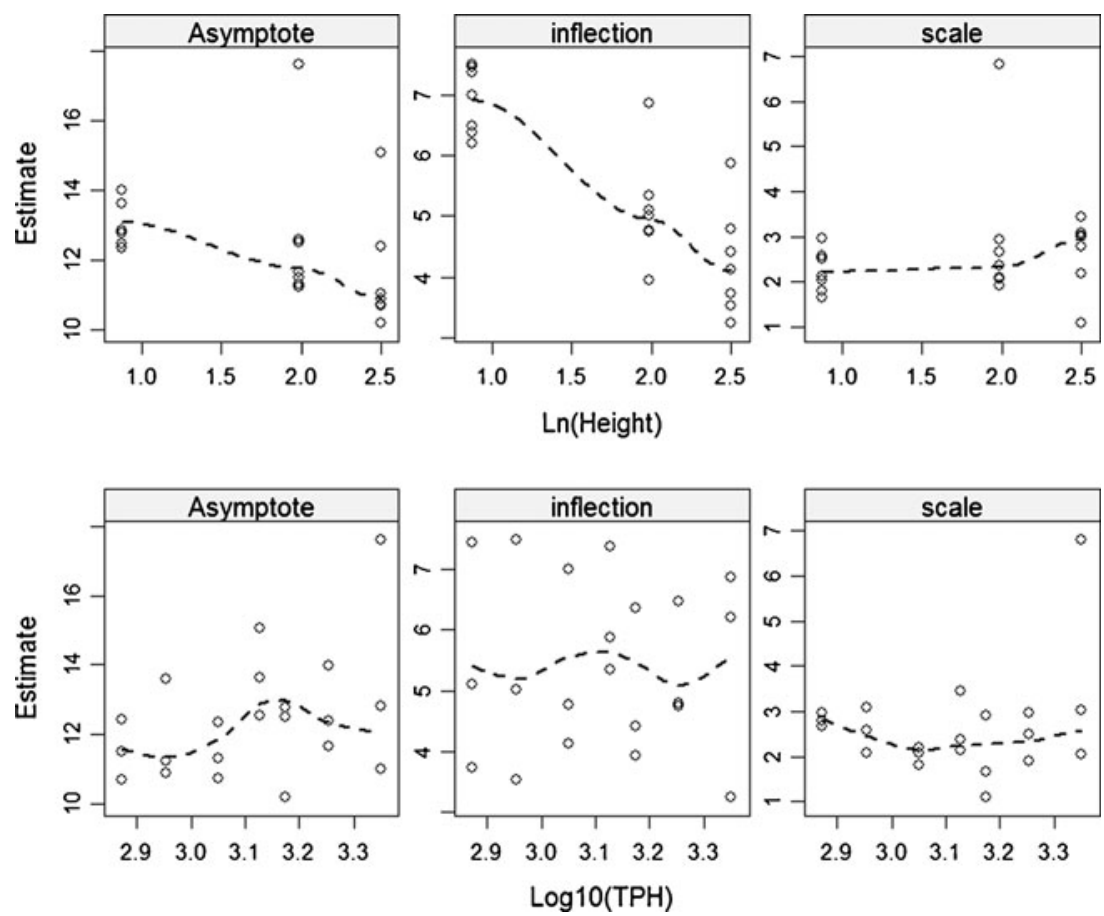

models such as Gaussian, exponential models, etc.) while modeling. The nonlinear mixed models were implemented using the nlme package available in R (Pinheiro et al. 2011).

\section{Results}

A full model with the fixed effect specification (linear height, TPH, and stem slenderness terms) along with block-plot-tree-height level random effects in all the parameters and a continuous autocorrelation structure was fitted initially. Then, the final model was achieved by dropping non-significant fixed and random effect terms from the model. A series of full and reduced models were compared using their fit statistics such as AIC and BIC to reach a final parsimonious model. The estimated parameters from the final model are presented in Table 2. The diagonal random effect variance-covariance structure of the final model was
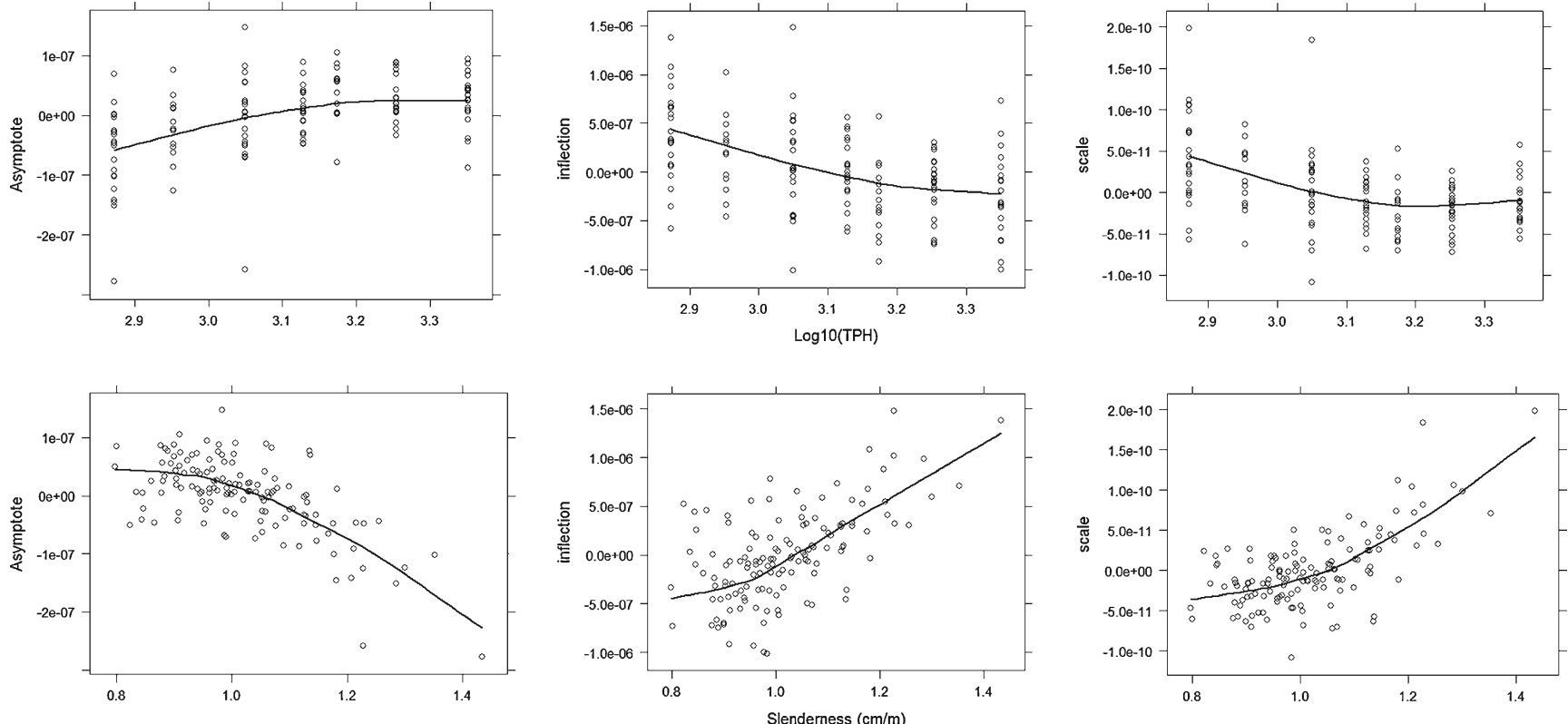

Fig. 3 Estimated tree level random effects plotted against height (ln of height), initial planting density $\left(\log _{10}\right.$ of trees/hectare (TPH)), and stem slenderness $(=\mathrm{DBH} /$ Total height of the tree) along with the smoothed LOESS line 
Table 2 Estimated fixed effect parameters along with respective standard error and the variance component associated with blockplot-tree level random effects of each parameter in the model from the final fitted model*

All the fixed effect parameters are significant at 0.05 level

\begin{tabular}{lrc}
\hline Parameters & Estimate & Standard error \\
\hline$\beta_{00}$ & 13.48 & 0.24 \\
$\beta_{10}$ & 10.47 & 1.65 \\
$\beta_{11}$ & -3.09 & 0.52 \\
$\beta_{12}$ & 0.52 & 0.16 \\
$\beta_{13}$ & -1.45 & 0.40 \\
$\beta_{14}$ & 3.64 & 0.57 \\
$\beta_{20}$ & -2.46 & 0.48 \\
$\beta_{21}$ & 0.79 & 0.07 \\
$\beta_{22}$ & 3.69 & 0.48 \\
$\sigma_{b_{0 i}}^{2}$ & 0.03 & \\
$\sigma_{b_{0 i j k}}^{2}$ & 0.23 & \\
$\sigma_{b_{1 j i k}}^{2}$ & 0.10 & \\
$\sigma_{b_{1 j j k l}}^{2}$ & 0.37 & \\
$\sigma_{b_{2 i j k}}^{2}$ & 0.12 & \\
$\sigma_{b_{2 i j k l}}^{2}$ & 0.07 & \\
$\sigma_{e}^{2}$ & 0.57 & \\
\hline
\end{tabular}

relaxed by assuming a general positive-definite matrix $(\mathrm{AIC}=2,545.03)$ where all the random effects in the model were allowed to covary with each other at each grouping level (block-plot-tree-height), but this did not show an improvement compared to the diagonal structure ( $\mathrm{AIC}=2,543.33)$. The form of the final model is

$y_{i j k l m}=\frac{\beta_{0, i j k l}}{1+e^{\left(\frac{\beta_{1, i j k l}-R_{i j k l m}}{\beta_{2, j k l}}\right)}}+\varepsilon_{i j k l m}$

$\beta_{0, i j k l}=\beta_{00}+b_{0 i}+b_{0 i j k}$

$$
\begin{aligned}
\beta_{1, i j k l}= & \beta_{10}+\beta_{11} \ln (\text { height })+\beta_{12} \ln (\text { height })^{2} \\
& +\beta_{13} \log _{10}(\mathrm{TPH})+\beta_{14} \mathrm{SL}+b_{1 i j k}+b_{1 i j k l}
\end{aligned}
$$

$\beta_{2, i j k l}=\beta_{20}+\beta_{21} \ln ($ height $)+\beta_{22} \mathrm{SL}+b_{2 i j k}+b_{2 i j k l}$

The influence of sampling height, TPH, and slenderness on the asymptotic parameter $\left(\boldsymbol{\beta}_{0}\right)$ was absent and dropped from the final model. Even though trends in maximum MOE with height (Fig. 2) and TPH (Fig. 3) were observed, the magnitude of change in $\boldsymbol{\beta}_{0}$ was negligible. For example, the average asymptotic MOE estimated from fitting the model to each sampling height-TPH combination was $13.09 \mathrm{GPa}(2.4 \mathrm{~m}), 12.63 \mathrm{GPa}(7.3 \mathrm{~m})$, and $11.57 \mathrm{GPa}$ $(12.2 \mathrm{~m})$ at the three sampling heights, respectively (Fig. 2).Significant block-to-block and between tree variability was observed in the asymptotic parameter.
All the explanatory variables (sampling height, TPH, and stem slenderness) were found to have a significant influence on the inflection point parameter $\left(\boldsymbol{\beta}_{1}\right)$. A quadratic height effect was significant for inflection point estimates, corroborated by Fig. 2. In this study, as defined in the previous section, the inflection point represents distance from the pith of a tree where MOE is half of the asymptotic MOE (i.e., 6.74 GPa based on the final model). As we can see from Figs. $4 \mathrm{~b}$ and 5 , the value of the point of inflection decreased while moving up the tree indicating that the tree reaches an MOE of $6.74 \mathrm{GPa}$ more quickly with an increase in sampling height. Based on Fig. 5, a slower rate of change in MOE was observed at lower portions of the stem and a faster rate as we go up in the tree. In addition to sampling height, a linear effect of TPH and stem slenderness on the inflection point parameter was observed in the final fitted model (Fig. 4b). It was observed that the point of inflection decreased with an increase in planting density. In addition, between tree variability and height-to-height variability within a stem was significant for the inflection parameter.

A linear trend in the scale parameter $\left(\boldsymbol{\beta}_{2}\right)$, corresponds to the distance between inflection point $\left(\boldsymbol{\beta}_{1}\right)$ and the point where the MOE is $\beta_{0} /\left(1+e^{-1}\right)$, with sampling height and stem slenderness was significant based on the final fitted model (Fig. 4c). Thus, $\boldsymbol{\beta}_{1}+\boldsymbol{\beta}_{2}$ is approximately equivalent to the distance from the pith where $\mathrm{MOE}=0.73 \boldsymbol{\beta}_{0}$, i.e., based on the estimated parameters, $9.86 \mathrm{GPa}$. A linear increase in scale parameter with sampling height was evident from the model and indicates that the rate of increase in MOE from pith-tobark will be slow near the base of the tree but will be faster up the tree. Between tree variability and height-to-height variability within a stem was significant for the scale parameter.

The final nonlinear mixed model can be used for making predictions at different levels of interest (such as block, tree, and $\log$ ) and is presented in Fig. 6. Based on Fig. 6, the model makes reasonably good predictions of MOE variation from pith-to-bark at different heights within a tree.

\section{Discussion}

Initial planting density is an important management tool in coniferous plantations because of its influence on height and diameter growth and thus final yield. At the same time, planting density has significant influence on within tree variability in MOE for coniferous plantation species \{loblolly pine in USA, radiata pine (Pinus radiata D. Don) in New Zealand, black spruce [Picea mariana (Mill.) Britton, Sterns \& Poggenb.] in Canada, and sitka spruce [Picea sitchensis (Bong.) Carr.] in the UK\}. Based on this study, initial planting density primarily influences the rate of change in MOE from pith-to-bark, which is also influenced by sampling height. Stem slenderness also has a significant 
Fig. 4 Plot showing the influence of height, trees/ hectare (TPH) and stem slenderness (ratio of diameter at breast height to the total height of tree) on each coefficient in the model (a)

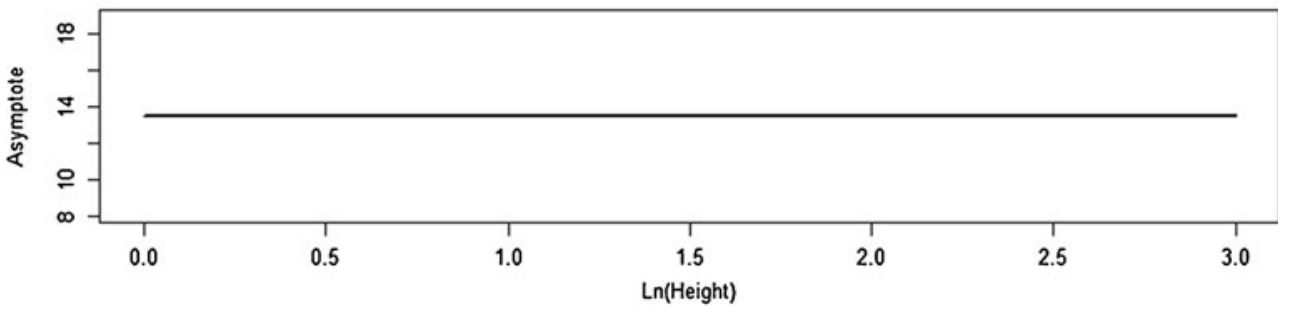

(b)

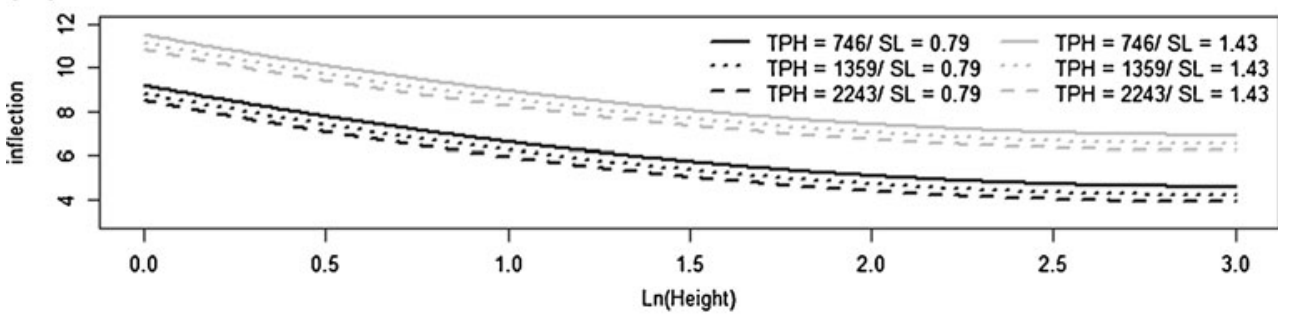

(c)

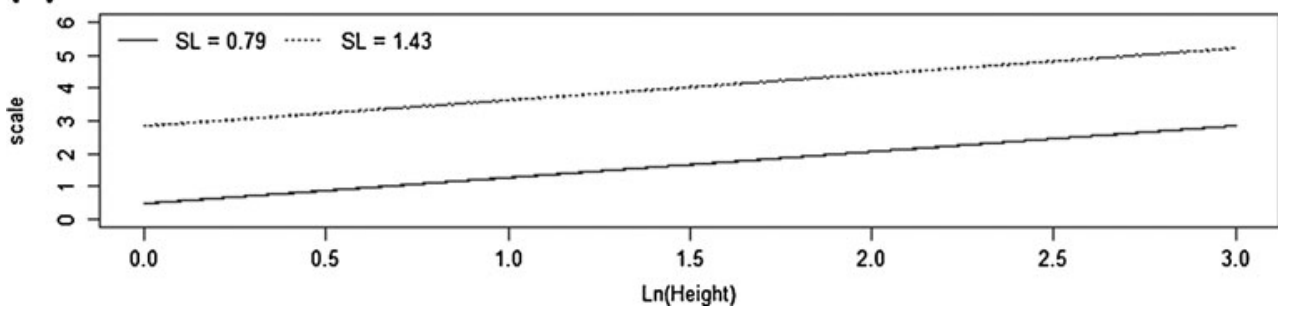

influence on the rate of change in MOE from pith-to-bark. As planting density increases, the proportion of corewood decreases, and hence, the overall stiffness of the tree increases. Zhang et al. (2002) observed a significant decrease in strength and stiffness of lumber produced from trees planted at lower

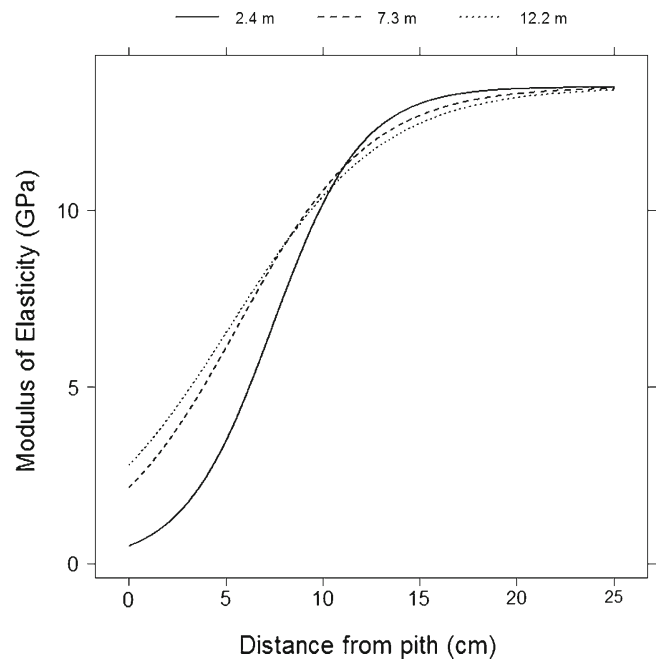

Fig. 5 Plot showing pith-to-bark MOE variation in a tree at different sampling heights, assuming that diameter is equal at all heights, initial planting density was 1,358 trees/hectare and stem slenderness was adjusted to the observed mean DBH $(27.02 \mathrm{~cm})$ and mean total height $(25.8 \mathrm{~m})$ of the data stand density (1,372 trees/hectare). They have also reported that the stiffness of lumber from plantation grown black spruce was $28.9 \%$ less than the stiffness of lumber from natural stands. Since a significant amount of the wood presently sold in the market is produced from fast grown short rotation loblolly pine (according to Wear and Greis (2002), around $16 \%$ ), it is important that both growers and buyers of this species understand the influence of different management practices (here planting density) on the strength of lumber produced.

No systematic variation was observed for the asymptote (the maximum outerwood MOE) with sampling height, stem slenderness, or initial planting density. The lack of influence of height on the asymptotic parameter indicates that wood produced after a certain cambial age, or distance from pith, at any height of the tree will have the same maximum outerwood MOE (asymptotic MOE), assuming that the trees grows old enough to reach that cambial age or diameter limit. This is evident from Fig. 5, where MOE profiles predicted using the final model parameters at the three sampling heights are presented (an equal diameter was assumed at all heights). It should also be noted that the range of heights sampled are limited (only three heights were sampled per stem) in this study, and therefore, we might not adequately express the variation in the asymptotic parameter with sampling height. Similarly, stem slenderness 
Fig. 6 Plot of observed $(\mathrm{O})$ and predicted values (using both fixed and random effect estimates) from the final fitted model against distance from pith. Plots are arranged by block, tree, and log (block/tree/log)

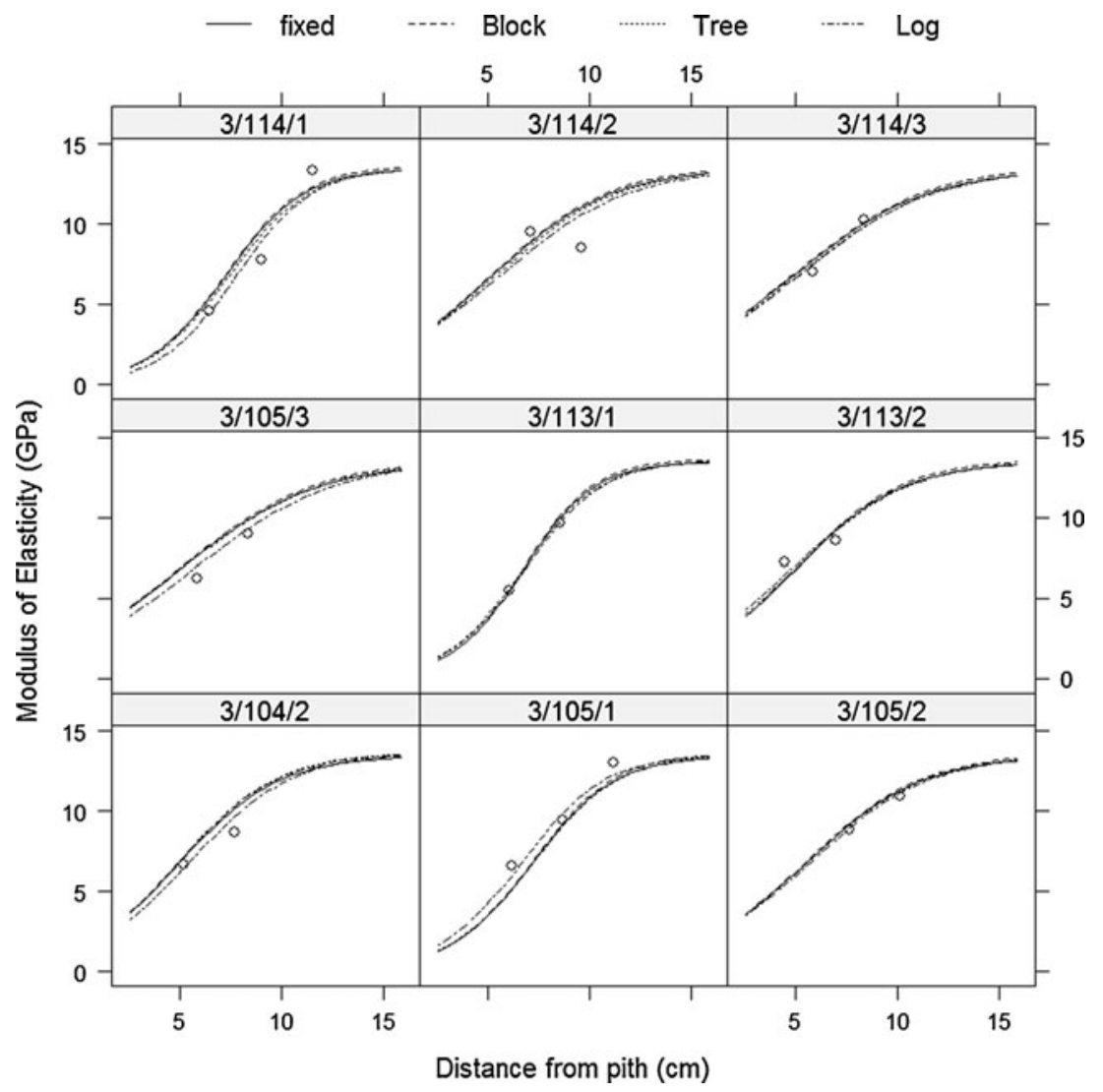

did not influence the asymptotic parameter. This indicates that irrespective of DBH and total height of the tree, the MOE reaches an upper plateau (asymptotic value) after a certain distance from the pith for all trees. On the contrary, Watt and Zoric (2010) observed a linear additive effect of stem slenderness on the mean sigmoidal trend in MOE with tree age for radiata pine growing on a wide environmental gradient across New Zealand. However, reasonable evidence exists to believe that the wood properties reach a plateau in the mature wood zone of a tree. Based on the data and the final model, the tree will attain a maximum outerwood MOE irrespective of initial planting density or sampling height, $\mathrm{DBH}$, and total height.

On the other hand, the inflection point parameter was influenced by sampling height, TPH, and stem slenderness. The difference in the rate of change in MOE from pith-tobark at different heights of a tree is clearly due to the interaction of specific gravity (SG) and microfibril angle (MFA) within a tree (Cave and Walker 1994; Megraw et al. 1999). In loblolly pine, SG and MFA together explained $76-96 \%$ of variation in MOE, though the relationship depended upon the distance from the pith and height within a tree (Megraw et al. 1999). Megraw et al. (1999) observed a slower rate of decrease in MFA from pith-to-bark at the base of the tree (at heights $<3 \mathrm{~m}$ ) but a faster rate of decrease in MFA above $3 \mathrm{~m}$. Jordan et al. $(2005 ; 2006)$ also observed similar trends in pith-to-bark MFA variation with height in loblolly pine. However, SG increases from pith-to-bark at a consistent rate at all heights in loblolly pine with a downward shift in the pith-to-bark profiles with increasing height (Megraw et al. 1999; Mora et al. 2007; Jordan et al. 2008). Thus, wood of given SG from the base of a tree is going to have a lower MOE due to high MFA at the base and vice versa. Similar trends were observed in radiata pine, where density alone explained the majority of variation in outerwood MOE (owing to consistent MFA), while for corewood, MOE was influenced by both density and MFA, with MFA sometimes having a stronger relationship with MOE than density (Cown et al. 1999; Ivkovic et al. 2009; Watt et al. 2010).

The decrease in inflection point with increase in TPH indicates that planting density influences the diameter of corewood, with trees at higher planting densities having a small diameter corewood with much stiffer wood than trees at lower planting densities (Larson et al. 2001). Decrease in stiffness in response to a decrease in initial planting density has been observed in loblolly pine (Clark and Saucier 1989; Clark et al. 2008; Roth et al. 2007), radiata pine (Lasserre et al. 2009; Watt and Zoric 2010), black spruce (Zhang et al. 2002), and in sitka spruce (Brazier and Mobbs 1993; Moore et al. 2009). As the initial planting density increases, trees have to compete against each other for resources (crown competition for light) at an earlier age and thus tend to restrict early age diameter growth. Roth et al. (2007) found that increasing planting density from 1,334 to 2,990 TPH increased dynamic MOE by $31 \%$ and decreased diameter by $28 \%$. 
Stem slenderness, a measure of individual tree DBH and total height, was found to have a significant influence on the MOE of trees in several previous studies in loblolly pine (Roth et al. 2007) and in radiata pine (Lasserre et al. 2009; Watt and Zoric 2010; Watt et al. 2010). As trees get more slender (i.e., a tall tree with small DBH), the inflection point occurs at a shorter distance from the pith reducing the proportion of corewood and hence increasing whole tree stiffness. Based on the model, the rate of increase in MOE will be faster (i.e., will reach $6.7 \mathrm{GPa}$ ) in the corewood zone as trees get more slender. This is clearly evident from Fig. $4 \mathrm{~b}$, where the inflection point estimate increases with an increase in stem slenderness, i.e., as trees are shorter and have larger DBH.

The nonlinear mixed model successfully accounted for the variability in the profiles from block-to-block, tree-totree, and log-to-log (essentially the different sampling heights). It proved to be a successful method as it could account for the large variability within the data. Significant tree-to-tree variability in asymptote, inflection point and scale parameter indicates tree-to-tree variability in $\mathrm{MOE}$ curve shape. Similarly, a significant height random effect assumes a constant correlation of observed MOE across tree height.

In conclusion, a three-parameter logistic function was proposed to model the pith-to-bark variation in MOE at different heights for loblolly pine. Based on the final model, it was found that the rate at which MOE profiles change from pith-to-bark within a tree is influenced by height on the stem, DBH, and total tree height, and the initial planting density of the stand. It was also observed that lower planting density decreases the proportion of corewood produced within a stem.

Acknowledgments The authors would like to thank International Paper for providing the samples used in this study and industrial partners of the Wood Quality Consortium at the University of Georgia for financial support.

Funding Wood Quality Consortium at the University of Georgia.

\section{References}

Antony F, Jordan L, Schimleck LR, Clark A, Souter RA, Daniels RF (2011) Regional variation in wood modulus of elasticity (stiffness) and modulus of rupture (strength) of planted loblolly pine in the United States. Can J For Res 41:1522-1533

ASTM Standards D143 1994 (2009). Standard test methods for small clear specimens of timber. ASTM International, West Conshohocken, PA, 2006, doi:10.1520/D0143-09, www.astm.org.

Baldwin VC, Peterson KD, Clark A, Ferguson RB, Strub MR, Bower DR (2000) The effects of spacing and thinning on stand and tree characteristics of 38-year-old Loblolly Pine. For Ecol Manage 137:91-102
Biblis E, Meldahl R (2006) Flexural properties of small, clear wood specimens obtained from two 20 -year-old loblolly pine plantations planted at 6-by 6-foot and 12-by 12 -foot spacings. For Prod J 56:56-58

Biblis EJ, Brinker R, Carino HF, Mckee CW (1993) Effect of stand age on flexural properties and grade compliance of lumber from loblolly-pine plantation timber. For Prod J 43:23-28

Brazier JD, Mobbs ID (1993) The Influence of planting distance on structural wood yields of unthinned Sitka spruce. Forestry 66:333-352

Cave ID, Walker J (1994) Stiffness of wood in fast grown plantation softwoods: the influence of microfibril angle. For Prod J 44:43-48

Clark A, Saucier JR (1989) Influence of initial planting density, geographic location, and species on juvenile wood formation in southern pine. For Prod J 39:42-48

Clark A, Jordan L, Schimleck L, Daniels RF (2008) Effect of initial planting spacing on wood properties of unthinned loblolly pine at age 21. For Prod J 58:78-83

Cown DJ, Herbert J, Ball RD (1999) Modeling Pinus radiata lumber characteristics. Part 1: mechanical properties of small clears. New Zeal J For Sci 29:203-213

Downes GM, Nyakuengama JG, Evans R, Northway R, Blakemore P, Dickson RL, Lausberg M (2002) Relationship between wood density, microfibril angle and stiffness in thinned and fertilized Pinus radiata. IAWA J 23:253-265

Evans R, Ilic J (2001) Rapid prediction of wood stiffness from microfibril, angle and density. For Prod J 51:53-57

He R (2004) Mixed effects modeling of wood properties of loblolly pine in the southeastern United States. Dissertation, University of Georgia, Athens

Ivkovic M, Gapare WJ, Abarquez A, Ilic J, Powell MB, Wu HX (2009) Prediction of wood stiffness, strength, and shrinkage in juvenile wood of radiata pine. Wood Sci Technol 43:237-257. doi:10.1007/s00226-008-0232-3

Jordan L, Daniels RF, Clark A, He R (2005) Multilevel nonlinear mixed-effects models for the modeling of earlywood and latewood microfibril angle. For Sci 51:357-371

Jordan L, He R, Hall DB, Clark A, Daniels RF (2006) Variation in loblolly pine cross-sectional microfibril angle with tree height and physiographic region. Wood Fiber Sci 38:390-398

Jordan L, Clark A, Schimleck LR, Hall DB, Daniels RF (2008) Regional variation in wood specific gravity of planted loblolly pine in the United States. Can J For Res 38:698-710

Larson PR, Kretschmann DE, Clark A, Isebrands JG (2001) Formation and properties of Juvenile Wood in Southern Pines a synopsis. USDA Forest Service, general technical report FPL-GTR-129 general technical report

Lasserre J-P, Mason EG, Watt MS, Moore JR (2009) Influence of initial planting spacing and genotype on microfibril angle, wood density, fibre properties and modulus of elasticity in Pinus radiata D. Don corewood. For Ecol Manage 258:1924-1931

Littell RC, Pendergast J, Natarajan R (2000) Modelling covariance structure in the analysis of repeated measures data. Stat Med 19:1793-1819

Macpeak MD, Burkart LF, Weldon D (1990) Comparison of grade, yield, and mechanical-properties of lumber produced from young fast-grown and older slow-grown planted slash pine. For Prod J 40:11-14

Megraw RA, Bremer D, Leaf G, Roers J Stiffness in loblolly pine as a function of ring position and height, and its relationship to microfibril angle and specific gravity. In: Third Workshop-Connection between Silviculture and Wood Quality through Modeling Approaches, La Londeles Maures, France, 1999. IUFRO, pp 341-349

Moore J, Achim A, Lyon A, Mochan S, Gardiner B (2009) Effects of early re-spacing on the physical and mechanical properties of Sitka spruce structural timber. For Ecol Manage 258:1174-1180 
Mora CR, Allen HL, Daniels RF, Clark A (2007) Modeling corewoodouterwood transition in loblolly pine using wood specific gravity. Can J For Res 37:999-1011

Pinheiro CJ, Bates DM (2000) Mixed effects models in S and S-plus. Springer, New York, p 528

Pinheiro CJ, Bates MD, DebRoy S, Sarkar D. R Core team (2011) Linear and nonlinear mixed effects models. R package version 2.13.

Plomion C, Leprovost G, Stokes A (2001) Wood formation in trees. Plant Physiol 127:1513-1523

Roth BE, Li X, Huber DA, Peter GF (2007) Effects of management intensity, genetics and planting density on wood stiffness in a plantation of juvenile loblolly pine in the southeastern USA. For Ecol Manage 246:155-162

Sharma M, Burkhart HE, Amateis RL (2002) Modeling the effect of density on the growth of loblolly pine trees. South J Appl For 26:124-133

Wang X (2003) Modeling changes in strength and stiffness of Loblolly pine wood. MS Thesis, University of Georgia, Athens

Watt MS, Zoric B (2010) Development of a model describing modulus of elasticity across environmental and stand density gradients in plantation-grown Pinus radiata within New Zealand. Can J For Res 40:1558-1566

Watt MS, Clinton PC, Parfitt RL, Ross C, Coker G (2009) Modelling the influence of site and weed competition on juvenile modulus of elasticity in Pinus radiata across broad environmental gradients. For Ecol Manage 258:1479-1488

Watt MS, Sorensson C, Cown DJ, Dungey HS, Evans R (2010) Determining the main and interactive effect of age and clone on wood density, microfibril angle, and modulus of elasticity for Pinus radiata. Can J For Res 40:1550-1557. doi:10.1139/X10-095

Wear DN, Greis JG (2002) Southern forest resource assessmentsummary of findings. J Forest 100:6-14

Zhang SY, Chauret G, Ren HQQ, Desjardins R (2002) Impact of initial spacing on plantation black spruce lumber grade yield, bending properties, and MSR yield. Wood Fiber Sci 34:460-475

Zhao DH, Kane M, Borders BE (2011) Growth responses to planting density and management intensity in loblolly pine plantations in the southeastern USA Lower Coastal Plain. Ann Forest Sci 68:625-635. doi:10.1007/s13595-011-0045-7 